\title{
Fenologia e biologia reprodutiva de duas espécies de Byrsonima Rich. (Malpighiaceae) em área de Cerrado no Nordeste do Brasil
}

\author{
Fernanda Nogueira Mendes ${ }^{1,3}$, Márcia Maria Corrêa Rêgo ${ }^{2}$ \& Patrícia Maia Correia de Albuquerque ${ }^{2}$ \\ ${ }^{1}$ Programa de Pós-graduação em Biodiversidade e Conservação, Universidade Federal do Maranhão - UFMA, \\ CEP 65080-581, São Luís, MA, Brasil \\ ${ }^{2}$ Laboratório de Estudos sobre Abelhas - LEA, Departamento de Biologia, \\ Universidade Federal do Maranhão - UFMA, CEP 65080-581, São Luís, MA, Brasil \\ ${ }^{3}$ Autor para correspondência: Fernanda Nogueira Mendes, e-mail: fnmodel@yahoo.com.br
}

MENDES, F.N., RÊGO, M.M.C. \& ALBUQUERQUE, P.M.C. Phenology and reproductive biology of two species of Byrsonima Rich. (Malpighiaceae) in Cerrado area in Northeastern Brazil. Biota Neotrop. 11(4): http://www.biotaneotropica.org.br/v11n4/en/abstract?article+bn02511042011

\begin{abstract}
The knowledge of the phenology patterns and of the floral biology, the determination of the role of the vectors of pollen flow, besides the understanding of the reproductive system, are fundamental points for the understanding of the reproductive biology of the species. The pollination ecology, reproductive system, flowering phenology and floral visitors of Byrsonima umbellata Mart. and B. rotunda Griseb. were studied in a Cerrado area, at Urbano Santos municipality, Maranhão State. B. umbellata presented extended flowering period (eight months) and $B$. rotunda showed brief flowering period (one month). The species had hermaphroditic flowers with diurnal anthesis. $B$. umbellata is facultatively self-incompatible, showing higher fruit production through cross-pollinators (46.6\%), and $B$. rotund $a$ is mainly self-compatible, with fruit production in all treatments, even through agamospermy (60\%), although higher production was achieved in geitonogamy (90\%). We observed 42 and 16 species of bees in B. umbellata and B. rotunda flowers, respectively. Centris aenea and C. (Trachina) sp.n. were considered the main pollinators of $B$. umbellata flowers and $C$. aenea of B. rotunda. Both Byrsonima species present important ecological function, representing important resources to several species of bees during flowering season deficit in the studied environment.
\end{abstract}

Keywords: breeding system, Centridini, pollination, Byrsonima umbellata, Byrsonima rotunda.

MENDES, F.N., RÊGO, M.M.C. \& ALBUQUERQUE, P.M.C. Fenologia e biologia reprodutiva de duas espécies de Byrsonima Rich. (Malpighiaceae) em área de Cerrado no Nordeste do Brasil. Biota Neotrop. 11(4): http://www.biotaneotropica.org.br/v11n4/pt/abstract?article+bn02511042011

Resumo: O conhecimento dos padrões fenológicos e da biologia floral, a determinação do papel dos vetores de fluxo de pólen, além do entendimento do sistema reprodutivo, são pontos fundamentais para a compreensão da biologia reprodutiva das espécies. Diante disso, o sistema reprodutivo, a fenologia da floração e os insetos visitantes de Byrsonima umbellata Mart. e B. rotunda Griseb. foram estudados em uma área de Cerrado, no município de Urbano Santos, Estado do Maranhão. Byrsonima umbellata apresenta longo período de floração (oito meses) e $B$. rotunda possui floração curta (um mês). Em ambas as espécies as flores são hermafroditas e as anteses diurnas. Byrsonima umbellata é facultativamente auto-incompatível, apresentando maior produção de frutos através da polinização cruzada (46,6\%), e B. rotunda é autocompatível, com produção de frutos em todos os experimentos, inclusive através da agamospermia (60\%), entretanto a maior produção ocorreu por geitonogamia (90\%). Foram observadas 42 e 16 espécies de abelhas nas flores de B. umbellata e B. rotunda, respectivamente. Centris aenea Lepeletier e $C$. (Trachina) sp.n. foram consideradas os polinizadores mais eficientes em flores de B. umbellata e $C$. aenea de $B$. rotunda. As duas espécies de Byrsonima apresentam importante função ecológica, pois representam importantes fontes de recursos a diversas espécies de abelhas em períodos de déficit de floração no ambiente estudado.

Palavras-chave: sistema reprodutivo, Centridini, polinização, Byrsonima umbellata, Byrsonima rotunda. 


\section{Introdução}

Malpighiaceae possui aproximadamente 71 gêneros e 1250 espécies (Lombello \& Forni-Martins 2003), das quais 85\% são neotropicais (Anderson 1979, Davis et al. 2001). No Brasil ocorrem aproximadamente 300 espécies, pertencentes a 32 gêneros, em diversas formações vegetais (Barroso et al. 1991). De acordo com Costa et al. (2006), estudos sobre ecologia da polinização de espécies de Malpighiaceae têm sido relatados desde a descoberta do óleo como recompensa floral para os polinizadores, principalmente abelhas dos gêneros Epicharis, Centris (Centridini), Tetrapedia (Tetrapediini), Paratetrapedia e Monoeca (Tapinotaspidini) (Vogel 1974, Buchmann 1987, Sazima \& Sazima 1989), as quais são adaptadas à coleta de óleo, possuindo estruturas especializadas em suas pernas (Vogel 1974, Neff \& Simpson 1981, Buchmann 1987).

O gênero Byrsonima Rich. possui 160 espécies, com cerca de 70 no Brasil (Flinte et al. 2003), onde são importantes componentes da flora do cerrado (Barros 1992). Por possuírem flores vistosas, frutos que atraem aves e pelo seu rápido crescimento, espécies de Byrsonima têm grande potencial ornamental e na recuperação de áreas degradadas (Anderson 1981). Trabalhos enfocando aspectos da biologia reprodutiva são encontrados para várias espécies, como B. crassifolia (L.) Kunth (Albuquerque \& Rêgo 1989, Rêgo \& Albuquerque 1989, Pereira \& Freitas 2002), B. coccolobifolia (Kunth) (Benezar \& Pessoni 2006), B. gardnerana A. Juss. (Bezerra et al. 2009) e B. sericea DC. (Teixeira \& Machado 2000, Rosa \& Ramalho 2007). Existem ainda os trabalhos de Barros (1992) com sete espécies em área de cerrado e Costa et al. (2006) com cinco espécies em área de dunas.

Em relação ao sistema reprodutivo, auto-incompatibilidade foi constatada em B. gardnerana (Bezerra et al. 2009), B. crassifolia (Rêgo \& Albuquerque 1989) e B. sericea (Teixeira \& Machado 2000; Costa et al. 2006). Barros (1992) observou certo grau de autocompatibilidade nas sete espécies de Byrsonima estudadas. Benezar \& Pessoni (2006) também comprovaram formação de frutos nos tratamentos de geitonogamia e autopolinização espontânea em flores de B. coccolobifolia.

O conhecimento de padrões fenológicos e da biologia floral, a determinação do papel dos vetores de fluxo de pólen, além do entendimento do sistema reprodutivo, são pontos fundamentais para a compreensão da biologia reprodutiva das espécies (Maués $\&$ Couturier 2002). Além disso, o conhecimento da diversidade dos polinizadores e das suas relações com a comunidade vegetal é de fundamental importância já que a polinização é um processo chave para a conservação da biodiversidade (Rodarte et al. 2008).

Diante disso, o presente trabalho teve como objetivo estudar comparativamente a biologia reprodutiva de duas espécies simpátricas de Byrsonima (B. umbellata Mart. e B. rotunda Griseb.) em ambiente de Cerrado no Estado do Maranhão, contribuindo com a obtenção de dados ainda inéditos ou pouco conhecidos relacionados às formas de reprodução e aos mecanismos de polinização destas espécies.

\section{Material e Métodos}

O estudo foi realizado de março de 2005 a fevereiro de 2007, em uma área do bioma Cerrado, no município de Urbano Santos,

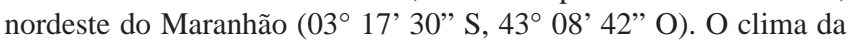
região é tropical megatérmico (tipo Aw, conforme classificação de Köppen), com pluviosidade anual em torno de 1800 mm, sendo os meses de dezembro a maio o período de concentração das chuvas. A temperatura média anual varia entre 26 e $27{ }^{\circ} \mathrm{C}$. A vegetação predominante na área é de Cerrado (sensu stricto), ocorrendo ainda floresta estacional semidecídua e manchas de vegetação mista (Maranhão 1984).
Para o estudo da fenologia reprodutiva de B. umbellata foi utilizada área amostral de 1 ha, onde 60 indivíduos adultos foram selecionados, marcados e monitorados mensalmente. Em outra área amostral de 1 ha foram selecionados aleatoriamente 50 indivíduos de $B$. rotunda, que foram monitorados semanalmente devido ao curto período de floração. As observações fenológicas foram realizadas de março de 2006 a fevereiro de 2007, registrando-se a presença das fenofases de floração (botão e flores) e frutificação (frutos imaturos e maduros). O pico de floração foi determinado quando mais de $50 \%$ dos ramos de cada indivíduo se encontravam floridos (Machado \& Semir 2006). O padrão de floração foi analisado conforme Newstrom et al. (1994).

A sincronia das fenofases reprodutivas foi analisada por meio do método do Índice de Atividade, que consiste na constatação da presença ou ausência da fenofase no indivíduo, não estimando intensidade ou quantidade (Bencke \& Morellato 2002). Este método permite quantificar a porcentagem de indivíduos da população que está manifestando determinado evento fenológico e também estima a sincronia entre os indivíduos de uma população. Os dados pluviométricos do período de estudo foram fornecidos pela Comercial e Agrícola Paineiras, que dispunha de pluviômetros próximos à área estudada.

Nas duas espécies foram realizadas observações sobre a morfologia floral ( $\mathrm{n}=20$ flores por espécie), tipo e número de inflorescências por indivíduo $(\mathrm{n}=20)$, número de botões por inflorescência $(n=30)$ e flores por inflorescência $(n=20)$. O processo de abertura e longevidade floral foi acompanhado das 6 às 17 horas em 40 botões por espécie (cinco por indivíduo), marcados na préantese. A viabilidade do pólen ( $\mathrm{n}=20$ botões) foi analisada pela técnica de coloração com carmim acético (Dafni 1992) em botões coletados na pré-antese.

A receptividade do estigma foi testada através de testes manuais de polinização cruzada (xenogamia) em 30 flores de cada espécie (Dafni et al. 2005), sendo 10 recém-abertas, 10 após 24 horas e 10 após 48 horas da abertura. Esta metodologia foi empregada por ser considerada de maior confiabilidade. Em seguida as flores foram isoladas por meio de sacos de voile e acompanhadas para verificar formação de fruto.

Para estudo do sistema de reprodução foram selecionados seis indivíduos de cada espécie, sendo realizados os seguintes tratamentos: a) Polinização cruzada (feita com pólen de uma flor recém aberta de indivíduo distante cerca de 100 m); b) Geitonogamia (pólen de outra flor do mesmo indivíduo), autopolinização manual (pólen da própria flor); c) Autopolinização espontânea (o botão permaneceu isolado sem nenhuma manipulação do mesmo), e d) Apomixia (emasculação sem qualquer tratamento, seguido de isolamento). Antes e após os experimentos, as flores foram ensacadas para evitar contato com os visitantes. Os experimentos foram realizados logo após a abertura das flores, sendo utilizadas 30 flores por tratamento.

Para verificar a polinização em condições naturais foram marcadas 30 flores (em seis indivíduos), com livre acesso aos visitantes florais. A partir dos resultados obtidos foram calculados o índice de autoincompatibilidade (ISI $=\%$ frutos formados por flores autopolinizadas manualmente/ \% flores submetidas à polinização cruzada) e a eficácia reprodutiva ( $\mathrm{ER}=\%$ frutos formados em condições naturais $/ \%$ frutos formados por polinização cruzada) (sensu Sobrevila \& Arroyo 1982).

Os visitantes florais das duas espécies foram coletados entre 6 e 17 horas, totalizando 187 horas de amostragem, sendo 132 horas para B. umbellata e 55 horas para B. rotunda. O comportamento dos visitantes nas flores foi registrado por meio de observações diretas, máquina fotográfica e filmadora, observando-se o horário de visita e o tipo de recurso floral coletado. De acordo com o comportamento, os visitantes foram categorizados em polinizadores (entram em 
contato com as estruturas reprodutivas da flor) ou pilhadores (não entram em contato).

Os exemplares coletados foram depositados na coleção de abelhas do Laboratório de Estudos sobre Abelhas da Universidade Federal do Maranhão (UFMA).

\section{Resultados}

\section{Fenologia reprodutiva}

A Figura 1 mostra as fenofases de floração e frutificação de Byrsonima umbellata e $B$. rotunda. $B$. umbellata apresentou período longo de floração (março a outubro), com todos os indivíduos selecionados floridos nos meses de junho e julho. Houve sincronia na frutificação dessa espécie entre os meses de junho e agosto e o período de desenvolvimento dos frutos foi de 30 a 45 dias. A floração de $B$. rotunda foi curta (outubro) e ocorreu após queimada natural, estando todos os indivíduos floridos na segunda semana do mês. A frutificação ocorreu da segunda semana de outubro à metade de novembro, com maior produção de frutos na primeira semana de novembro. O período de desenvolvimento dos frutos foi de aproximadamente 20 dias.

\section{Morfologia e biologia floral}

Byrsonima umbellata é um arbusto com altura média de 1,5 m, enquanto $B$. rotunda tem porte arbóreo a arbustivo com média de $2,6 \mathrm{~m}$ de altura. As duas espécies apresentam morfologia floral semelhante, possuindo flores hermafroditas, zigomorfas, pentâmeras, com uma pétala diferenciada (estandarte) e dez elaióforos (dois por sépala). As flores estão dispostas em inflorescências terminais do tipo racemo. Os frutos de ambas as espécies são drupáceos, com média de $5,25 \mathrm{~mm}( \pm 0,78)$ de diâmetro e cor amarela em $B$. rotunda e com $6,15 \mathrm{~mm}( \pm 1,13)$ de diâmetro e vermelhos em $B$. umbellata.

Em Byrsonima rotunda o comprimento das inflorescências $(13,6 \pm 3,3 \mathrm{~cm})$, o número de inflorescências por indivíduo $(195,2 \pm 236)$ e de botões por inflorescência $(29 \pm 8,7)$ é maior que em $B$. umbellata $(3,1 \pm 0,99 \mathrm{~cm} ; 124,9 \pm 140 ; 10,4 \pm 4,3$, respectivamente).

As flores das duas espécies possuem coloração branca, sendo as de $B$. umbellata maiores $(10,1 \pm 1,2 \mathrm{~mm}$ de diâmetro) que as de B. rotunda $(7,0 \pm 0,4 \mathrm{~mm})$. O androceu é constituído por dez estames com anteras introrsas de deiscência rimosa e pólen pulverulento com viabilidade de $94 \%$ em $B$. umbellata e $9 \%$ em B. rotunda. $\mathrm{O}$ gineceu é composto por cinco estigmas localizados abaixo das anteras em $B$. umbellata, e por três estigmas na mesma altura das anteras em $B$. rotunda. Não foi percebido nenhum odor nas flores das duas espécies.

As duas espécies têm flores com antese diurna, pois elas se encontram funcionais apenas durante o dia, com início do processo de abertura das flores ocorrendo entre 6 e 7 horas. Além do período da manhã, as flores de $B$. rotunda também abrem no fim da tarde (16-17 horas). A abertura das pétalas pode ocorrer de duas formas: sincrônica, com todas as pétalas abrindo ao mesmo tempo, ou sequencial, uma pétala por vez. Nas duas espécies, a antese iniciase com a separação das pétalas (com exceção do estandarte), evidenciando os estames e estigmas, e deiscência das anteras após uma ou duas horas. As flores ficam abertas e vistosas por até 48 horas; em seguida entram em processo de senescência, percebido pelo ressecamento dos estames, mudança de coloração da corola (do branco para o vermelho em $B$. umbellata) ou somente da pétala estandarte (do branco para o rosa em $B$. rotunda) e queda das pétalas após 24 ou 48 horas. Os estiletes permanecem até a formação do fruto.
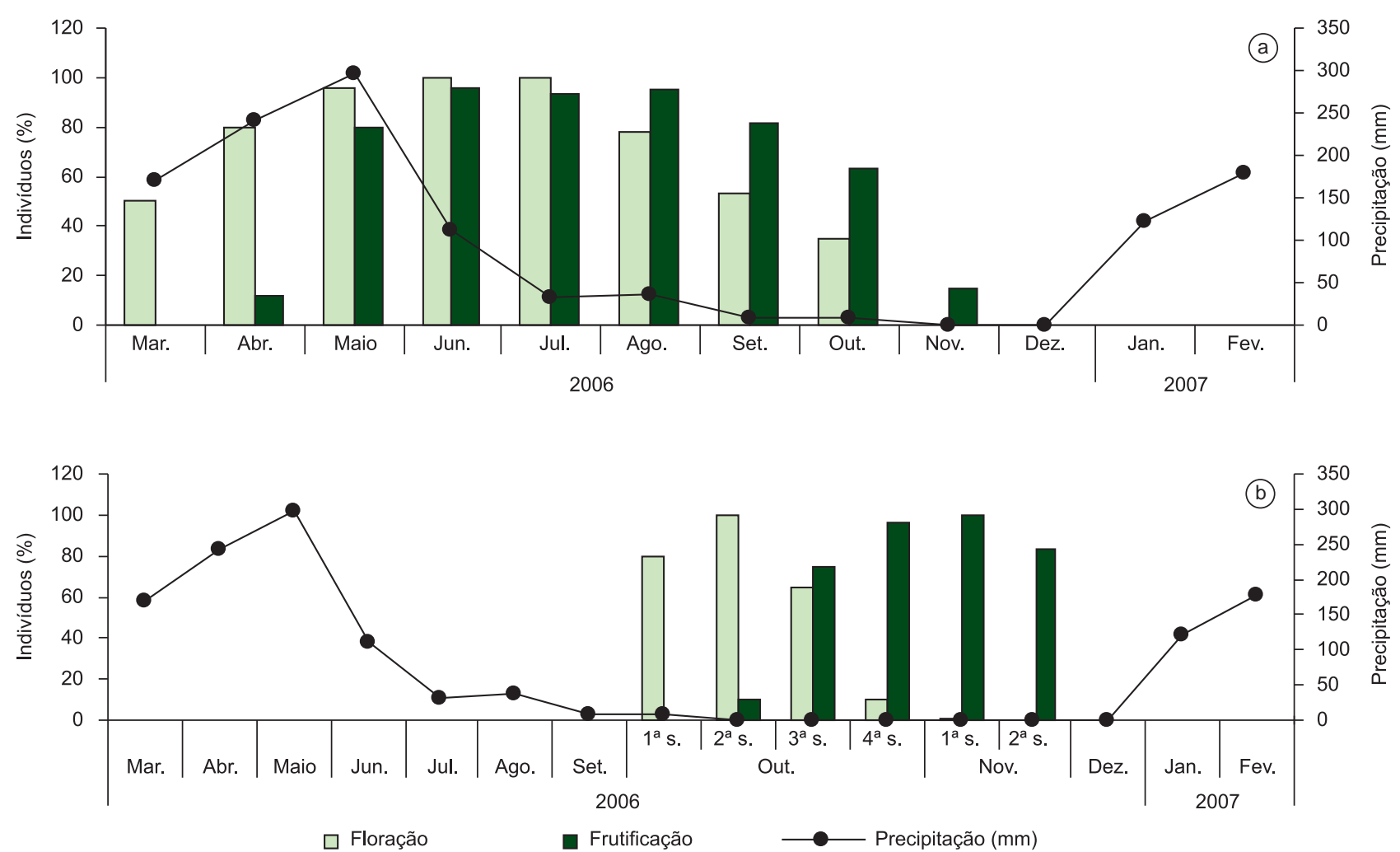

Figura 1. Porcentagem de indivíduos de a) Byrsonima umbellata; e b) B. rotunda em floração e frutificação de março/2006 a fevereiro/2007, em cerrado, Urbano Santos, Maranhão, Brasil.

Figure 1. Individuals percentage of a) Byrsonima umbellata; and b) B. rotunda in flowering and fructification from March/2006 to February/2007, Urbano Santos, Maranhão, Brazil. 
Foi observado até oito flores abertas/dia/inflorescência nos indivíduos de $B$. umbellata e até quatro em $B$. rotunda. A produção de óleo nos elaióforos foi observada em botões em pré-antese até 48 horas após a abertura da flor. Não foi observada produção de néctar nas flores das duas espécies. Os testes de polinização cruzada (xenogamia) mostraram que os estigmas estão receptivos desde o momento da abertura da flor até 48 horas após a antese nas duas espécies.

Um resumo das principais características morfológicas e estruturais das flores das duas espécies se encontra na Tabela 1.

\section{Sistema de reprodução}

Os resultados dos tratamentos de polinização encontram-se na Tabela 2. Em Byrsonima umbellata não houve formação de frutos através da apomixia (agamospermia) e da autopolinização espontânea. Houve baixa produção de frutos na autopolinização manual (13,3\%) e maior produção através da polinização cruzada (xenogamia - 46,6\%). A taxa de frutificação natural foi menor do que experimentalmente (polinização manual) (Tabela 2).

B. rotunda apresentou formação de frutos em todos os testes, inclusive na agamospermia, a qual apresentou sucesso similar à polinização natural (controle), com $60 \%$ de sucesso (Tabela 2). A maior taxa de frutificação foi obtida a partir dos tratamentos de geitonogamia (90\%) e xenogamia $(66,6 \%)$. A menor taxa de produção de frutos ocorreu na autopolinização espontânea (23,3\%) (Tabela 2).

De acordo com o índice de auto-incompatibilidade (ISI), $B$. rotunda é autocompatível e $B$. umbellata é facultativamente autoincompatível (Tabela 2). A eficácia reprodutiva (RE) foi 0,78 em B. umbellata e 0,90 em B. rotunda.

\section{Visitantes florais}

Os visitantes florais observados nas espécies de Byrsonima foram abelhas pertencentes às famílias Apidae ( $\mathrm{n}=40 \mathrm{spp}$.) e Halictidae $(\mathrm{n}=4)$, sendo registradas 42 espécies nas flores de $B$. umbellata e 16 nas de B. rotunda (Tabela 3). A tribo Centridini foi a mais representativa quanto ao número de espécies, com 19 em $B$. umbellata e oito em $B$. rotunda.

Trigona pallens (Fabricius), T. fulviventris Guérin e Centris maranhensis Ducke foram as espécies mais coletadas em B. umbellata $(28,5 ; 19,5$ e $7 \%$ do total coletado, respectivamente), enquanto que Centris aenea Lepeletier e T. pallens foram as mais coletadas em B. rotunda (86,4 e 4,2\%, respectivamente) (Tabela 3, Figura 2).

Foi observada maior atividade no período da manhã, principalmente entre 7 e 10 horas (Figura 3), e os períodos de maior abundância e diversidade de abelhas coletadas foram os meses de junho, julho e agosto em B. umbellata (Tabela 4), e na segunda semana de outubro em $B$. rotunda (Tabela 5), coincidindo com o pico de floração das duas espécies.

As abelhas Centridini foram observadas coletando principalmente óleo, tanto em flores quanto em botões. Centris maranhensis e C. bicolor Lepeletier foram vistas coletando exclusivamente óleo nas duas espécies de Byrsonima (Figura 2) e Epicharis analis Lepeletier coletando apenas pólen em flores de B. umbellata.

Para a coleta de óleo nas flores, as abelhas pousam sobre as mesmas, prendem-se através das mandíbulas na pétala estandarte e com os pentes basitarsais, presentes nos dois primeiros pares de pernas, raspam os elaióforos, que acabam rompidos. O óleo liberado é então coletado e transferido para as escopas das pernas posteriores. Já durante a coleta de óleo nos botões, espécies

Tabela 2. Resultados dos testes de polinização controlada em Byrsonima umbellata e B. rotunda em área de cerrado, Urbano Santos, Maranhão Brasil. ER - eficácia reprodutiva (\% frutos de polinização natural/ \% frutos de polinização cruzada); ISI - índice de auto-incompatibilidade (\% frutos de autopolinização manual/ \% frutos de polinização cruzada).

Table 2. Results of the controlled pollination tests of Byrsonima umbellata and B. rotunda in a cerrado area, Urbano Santos, MA, Brazil. $\mathrm{RE}=$ reproductive effectiveness (\% natural pollination fruits/ \%cross pollination fruits; ISI - selfincompatibility index (\%hand-pollination fruits/ \%cross pollination fruits).

\begin{tabular}{lcc}
\hline \multirow{2}{*}{ Tratamentos } & Byrsonima umbellata & Byrsonima rotunda \\
\cline { 2 - 3 } & $\boldsymbol{\%}\left(\mathbf{n}^{\mathbf{0}}\right.$ frutos / $\mathbf{n}^{\mathbf{0}}$ flores $)$ & $\mathbf{\%}\left(\mathbf{n}^{\mathbf{0}}\right.$ frutos / $\mathbf{n}^{\mathbf{0}}$ flores $)$ \\
\hline Agamospermia & $0(0 / 30)$ & $60(18 / 30)$ \\
Geitonogamia & $33,3(10 / 30)$ & $90(27 / 30)$ \\
Xenogamia & $46,6(14 / 30)$ & $66,6(20 / 30)$ \\
Autopolinização & $13,3(4 / 30)$ & $50(15 / 30)$ \\
manual & & \\
Autopolinização & $0(0 / 30)$ & $23,3(7 / 30)$ \\
espontânea & & $60(18 / 30)$ \\
Controle & $36,6(11 / 30)$ & 0,90 \\
ER & 0,78 & 0,75 \\
ISI & 0,28 & \\
\hline
\end{tabular}

Tabela 1. Características morfológicas, funcionais e estruturais das flores de Byrsonima umbellata e B. rotunda (Malpighiaceae) em área de Cerrado no município de Urbano Santos, MA.

Table 1. Morphological, functional and structural characteristics of Byrsonima umbellata and B. rotunda (Malpighiaceae) flowers in an area of Cerrado, at the municipality of Urbano Santos, MA.

\begin{tabular}{lcc}
\multicolumn{1}{c}{ Caracteres } & Byrsonima umbellata & Byrsonima rotunda \\
\hline Comprimento da inflorescência (cm) & $3,1 \pm 0,99$ & $13,6 \pm 3,3$ \\
Número de inflorescência por planta & $40,3 \pm 46,3$ & $195 \pm 236$ \\
Número de botões/inflorescência & $10,4 \pm 4,3$ & $29 \pm 8,7$ \\
Cor do eixo da inflorescência & Verde & Verde \\
Cor da flor nova & Branca & Branca \\
Cor da flor senescente & Vermelha & Branca com pétala estandarte rosa \\
Diâmetro floral (mm) & $10,1 \pm 1,2$ & $7 \pm 0,4$ \\
Altura dos estigmas em relação às anteras & Abaixo & Mesma altura \\
Horário de abertura (horas) & $6-7$ horas & $6-7$ e 17 horas \\
Longevidade (dias) & $4-5$ & $4-5$ \\
Viabilidade polínica & $94 \%$ & $9 \%$ \\
Produção de odor & Não & Não \\
Presença de néctar & Não & Não \\
\hline
\end{tabular}


Tabela 3. Visitantes florais de Byrsonima umbellata e $B$. rotunda, recurso coletado, número de indivíduos coletados e atuação na polinização. $(\mathrm{P}=$ pólen; $\mathrm{P}-\mathrm{O}=$ pólen e óleo; $\mathrm{O}=$ óleo; - = ausência de visitas; $\mathrm{PE}=$ Polinizador Efetivo - muito coletado; $\mathrm{PO}$ = Polinizador Ocasional - pouco coletado; $\mathrm{PI}$ = Pilhador .

Table 3. Floral visitors of Byrsonima umbellata and B. rotunda, collected resource, number of sampled individuals, and performance in pollination. $(\mathrm{P}=$ pollen; $\mathrm{P}-\mathrm{O}=$ pollen and oil; $\mathrm{O}=$ oil; - = no visits; $\mathrm{PE}=$ Effective Pollinator - much sampled; $\mathrm{PO}=$ Occasional Pollinator - bit sampled; PI = Nectar theft).

\begin{tabular}{|c|c|c|c|c|c|c|}
\hline \multirow[t]{2}{*}{ Visitantes } & \multicolumn{3}{|c|}{ Byrsonima umbellata } & \multicolumn{3}{|c|}{ Byrsonima rotunda } \\
\hline & $\begin{array}{l}\text { Recurso } \\
\text { coletado }\end{array}$ & $\begin{array}{c}\mathbf{N}^{\mathbf{0}} \\
\text { coletado }\end{array}$ & $\begin{array}{l}\text { Atuação na } \\
\text { polinização }\end{array}$ & $\begin{array}{l}\text { Recurso } \\
\text { coletado }\end{array}$ & $\begin{array}{c}\mathrm{N}^{\mathbf{0}} \\
\text { coletado }\end{array}$ & $\begin{array}{l}\text { Atuação na } \\
\text { polinização }\end{array}$ \\
\hline \multicolumn{7}{|l|}{ APIDAE } \\
\hline \multicolumn{7}{|l|}{ Centridini } \\
\hline Centris (Centris) aenea Lepeletier & $\mathrm{P}-\mathrm{O}$ & 50 & $\mathrm{PE}$ & $\mathrm{P}-\mathrm{O}$ & 268 & $\mathrm{PE}$ \\
\hline Centris (Centris) decolorata Lepeletier & $\mathrm{P}-\mathrm{O}$ & 7 & $\mathrm{PO}$ & - & - & - \\
\hline Centris (Centris) flavifrons (Fabricius) & $\mathrm{P}-\mathrm{O}$ & 1 & $\mathrm{PO}$ & $\mathrm{P}-\mathrm{O}$ & 5 & $\mathrm{PO}$ \\
\hline Centris (Centris) spilopoda Moure & $\mathrm{P}-\mathrm{O}$ & 3 & $\mathrm{PO}$ & $\mathrm{P}-\mathrm{O}$ & 5 & $\mathrm{PO}$ \\
\hline Centris (Hemisiella) tarsata Smith & $\mathrm{P}-\mathrm{O}$ & 9 & $\mathrm{PO}$ & $\mathrm{P}-\mathrm{O}$ & 2 & $\mathrm{PO}$ \\
\hline Centris (Hemisiella) trigonoides Lepeletier & $\mathrm{P}-\mathrm{O}$ & 2 & $\mathrm{PO}$ & - & - & - \\
\hline Centris (Heterocentris) analis (Fabricius) & $\mathrm{P}-\mathrm{O}$ & 1 & $\mathrm{PO}$ & - & - & - \\
\hline Centris (Ptilotopus) denudans Lepeletier & $\mathrm{O}$ & 4 & $\mathrm{PO}$ & - & - & - \\
\hline Centris (Ptilotopus) maranhensis Ducke & $\mathrm{O}$ & 59 & $\mathrm{PO}$ & $\mathrm{O}$ & 1 & $\mathrm{PO}$ \\
\hline Centris (Ptilotopus) sponsa Smith & $\mathrm{O}$ & 23 & $\mathrm{PO}$ & $\mathrm{P}-\mathrm{O}$ & 2 & $\mathrm{PO}$ \\
\hline Centris (Trachina) fuscata Lepeletier & $\mathrm{P}-\mathrm{O}$ & 3 & $\mathrm{PO}$ & - & - & - \\
\hline Centris (Trachina) longimana Fabricius & $\mathrm{P}-\mathrm{O}$ & 3 & $\mathrm{PO}$ & - & - & - \\
\hline Centris (Trachina) sp.n. & $\mathrm{P}-\mathrm{O}$ & 18 & PE & - & - & - \\
\hline Centris (Xanthemisia) bicolor Lepeletier & $\mathrm{O}$ & 2 & $\mathrm{PO}$ & $\mathrm{O}$ & 1 & $\mathrm{PO}$ \\
\hline Centris sp. 1 & $\mathrm{P}-\mathrm{O}$ & 1 & $\mathrm{PO}$ & - & - & - \\
\hline Centris sp.2 & $\mathrm{P}-\mathrm{O}$ & 1 & $\mathrm{PO}$ & - & - & - \\
\hline Centris sp. 3 & $\mathrm{P}-\mathrm{O}$ & 1 & $\mathrm{PO}$ & - & - & - \\
\hline Epicharis (Epicharis) bicolor Smith & $\mathrm{P}-\mathrm{O}$ & 5 & $\mathrm{PO}$ & $\mathrm{P}-\mathrm{O}$ & 4 & PO \\
\hline Epicharis (Triepicharis) analis Lepeletier & $\mathrm{P}$ & 1 & $\mathrm{PO}$ & - & - & - \\
\hline \multicolumn{7}{|l|}{ Meliponini } \\
\hline Frieseomelitta flavicornis (Fabricius) & $\mathrm{P}$ & 2 & PI & $\mathrm{P}$ & 1 & PI \\
\hline Frieseomelitta silvestrii (Friese) & $\mathrm{P}$ & 8 & PI & - & - & - \\
\hline Frieseomelitta sp. & $\mathrm{P}-\mathrm{O}$ & 41 & PI & - & - & - \\
\hline Paratrigona lineata (Lepeletier) & $\mathrm{P}$ & 4 & PI & - & - & - \\
\hline Partamona sp. & $\mathrm{P}$ & 1 & PI & - & - & - \\
\hline Tetragona quadrangula (Lepeletier) & $\mathrm{P}$ & 3 & PI & $P$ & 1 & PI \\
\hline Tetragonisca angustula (Latreille) & $\mathrm{P}$ & 4 & PI & - & - & - \\
\hline Trigona fulviventris Guérin & $\mathrm{P}$ & 164 & $\mathrm{PO}$ & $\mathrm{P}$ & 3 & PI \\
\hline Trigona fuscipennis Friese & - & - & - & $\mathrm{P}$ & 1 & PI \\
\hline Trigona pallens (Fabricius) & $\mathrm{P}$ & 240 & $\mathrm{PO}$ & $\mathrm{P}$ & 13 & PO \\
\hline Trigonisca intermedia Moure & $\mathrm{P}$ & 1 & PI & - & - & - \\
\hline Trigonisca sp.n. & $\mathrm{P}$ & 5 & PI & - & - & - \\
\hline \multicolumn{7}{|l|}{ Tapinotaspidini } \\
\hline Paratetrapedia (Amphipedia) sp. n. & $\mathrm{P}-\mathrm{O}$ & 8 & $\mathrm{PO}$ & $\mathrm{O}$ & 1 & $\mathrm{PO}$ \\
\hline Paratetrapedia leucostoma (Cockerell) & $\mathrm{P}-\mathrm{O}$ & 52 & $\mathrm{PO}$ & - & - & - \\
\hline Paratetrapedia testacea (Smith) & $\mathrm{P}-\mathrm{O}$ & 1 & $\mathrm{PO}$ & - & - & - \\
\hline Paratetrapedia sp.1 & $\mathrm{P}-\mathrm{O}$ & 21 & $\mathrm{PO}$ & $\mathrm{O}$ & 1 & PO \\
\hline Paratetrapedia sp.2 & $\mathrm{P}-\mathrm{O}$ & 23 & $\mathrm{PO}$ & - & - & - \\
\hline Xanthopedia globulosa (Friese) & - & - & - & $\mathrm{O}$ & 1 & $\mathrm{PO}$ \\
\hline \multicolumn{7}{|l|}{ Tetrapediini } \\
\hline Tetrapedia diversipes Klug & $\mathrm{P}-\mathrm{O}$ & 31 & $\mathrm{PO}$ & - & - & - \\
\hline Tetrapedia $\mathrm{sp} .1$ & $\mathrm{O}$ & 3 & PI & - & - & - \\
\hline Tetrapedia sp. 2 & $\mathrm{O}$ & 2 & PI & - & - & - \\
\hline \multicolumn{7}{|l|}{ HALICTIDAE } \\
\hline \multicolumn{7}{|l|}{ Augochlorini } \\
\hline Augochlora sp.1 & $\mathrm{P}$ & 5 & $\mathrm{PO}$ & - & - & - \\
\hline Augochlora sp.2 & $\mathrm{P}$ & 2 & $\mathrm{PO}$ & - & - & - \\
\hline Augochlora sp.3 & $\mathrm{P}$ & 25 & $\mathrm{PO}$ & - & - & - \\
\hline Augochlora sp.4 & $\mathrm{P}$ & 1 & $\mathrm{PO}$ & - & - & - \\
\hline Total & - & 841 & - & - & 310 & - \\
\hline
\end{tabular}


como Centris flavifrons (Fabricius) e as do subgênero Ptilotopus, equilibram-se na própria inflorescência com auxílio das pernas posteriores e raspam todas as glândulas, transferindo o óleo para a escopa ao deixar o botão, por meio de vôos estacionários próximos às inflorescências visitadas. Já $C$. (Trachina) sp. n. curva-se sobre o botão e prende-se no pedicelo com auxílio das pernas posteriores, realizando a raspagem do óleo com os outros pares de pernas (Figura 2).

Durante a coleta de pólen, as pernas anteriores e medianas permanecem imóveis sobre os elaióforos e a abelha vibra o corpo ("buzz-pollination"), pressionando as anteras e elevando as pernas posteriores ao mesmo tempo. A transferência dos grãos de pólen é realizada durante vôos estacionários por meio das pernas medianas, com as quais as abelhas raspam o pólen da parte ventral do tórax, depositando-o nas escopas. Alguns indivíduos de Epicharis (Epicharis) bicolor Smith penduravam-se nas folhas através da mandíbula para realizar a transferência do pólen.

As abelhas Centridini podem ainda alternar a coleta de pólen com a coleta de óleo ou coletar os dois recursos quase ao mesmo tempo, raspando os elaióforos e vibrando logo em seguida, sem sair da flor. Assim que saem, elas transferem rapidamente o pólen e o óleo para as escopas à procura de outra flor. Tanto durante a coleta de pólen quanto durante a coleta de óleo nas flores, a região de deposição dos

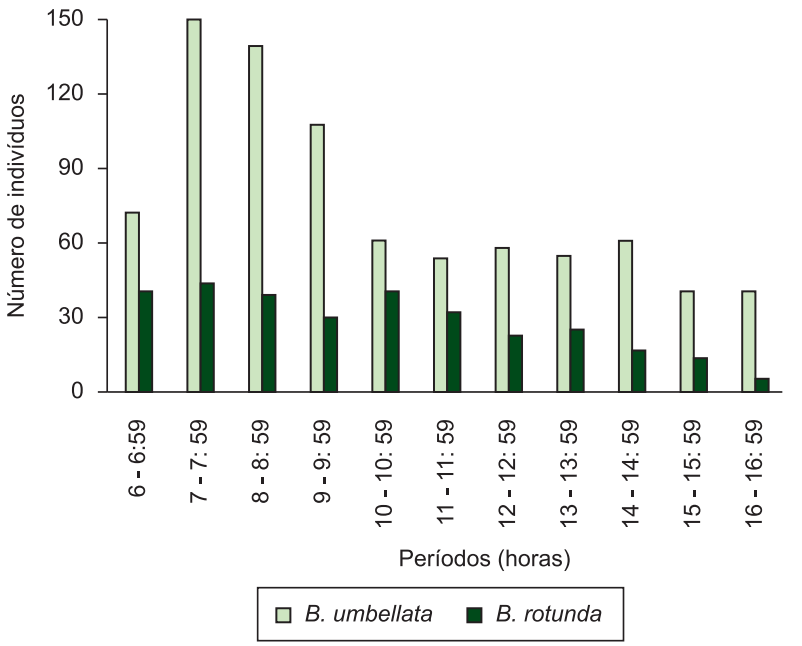

Figura 3. Número de abelhas visitantes coletadas em flores de Byrsonima umbellata e B. rotunda por período de coleta no Cerrado de Urbano Santos, MA, Brasil.

Figure 3. Number of bee visitors collected in flowers of Byrsonima umbellata and $B$. rotunda by collection time at the Cerrado of Urbano Santos, MA, Brazil.
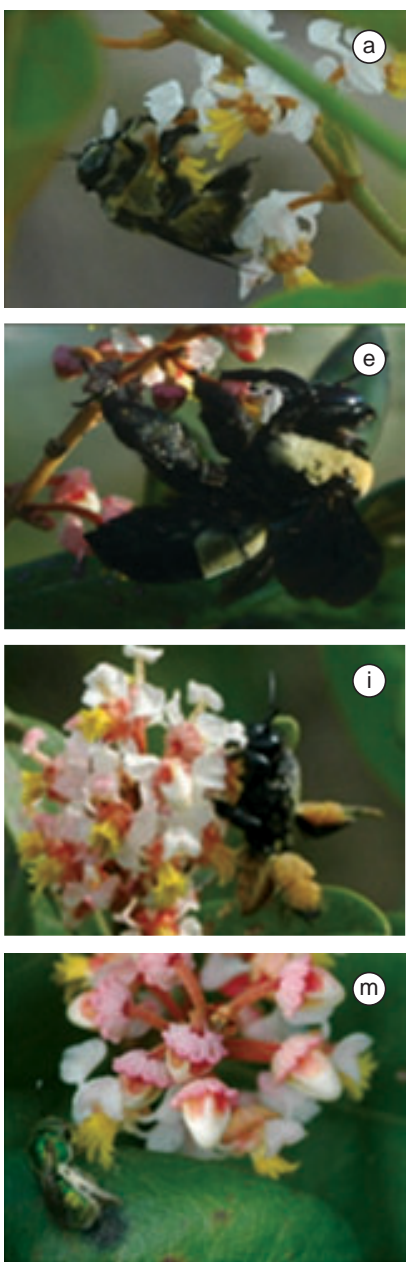
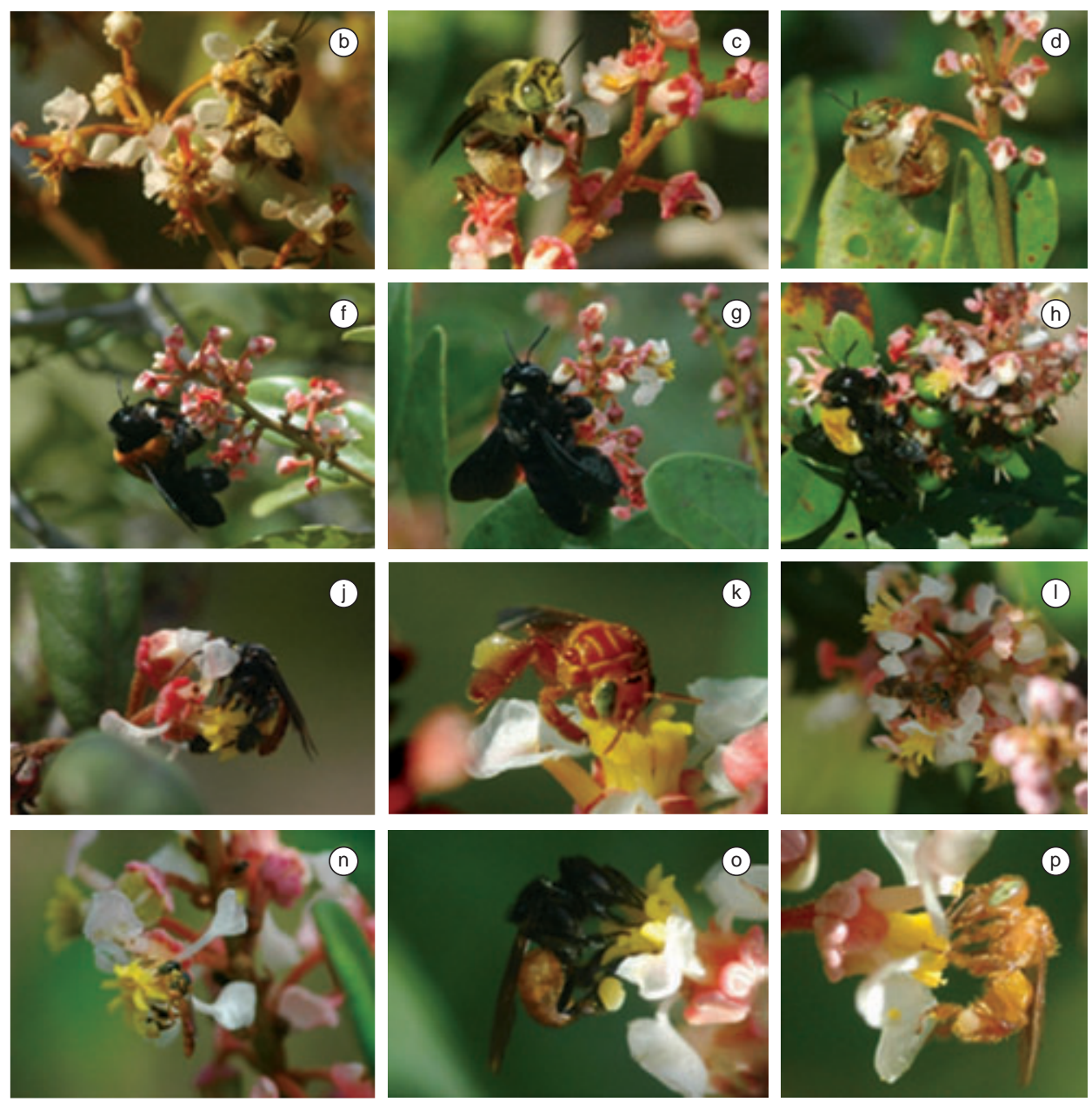

Figura 2. Abelhas visitantes de Byrsonima rotunda (a e b) e B. umbellata (c-p): a) Centris flavifrons; b) Centris aenea; c) Centris tarsata; d) Centris (Trachina) sp. n.; e) Centris (Ptilotopus) sponsa; f) Centris (P.) denudans; g) Centris (P.) maranhensis; h) Centris bicolor; i) Epicharis bicolor; j) Paratetrapedia leucostoma; k) Paratetrapedia (Amphipedia) sp. n.; 1) Frieseomelitta sp.; m) Augochlora sp.; n) Tetragonisca angustula; o) Trigona fulviventris; p) Trigona pallens.

Figure 2. Bees visitors of Byrsonima rotunda (a e b) e B. umbellata (c-p): a) Centris flavifrons; b) Centris aenea; c) Centris tarsata; d) Centris (Trachina) sp. n.; e) Centris (Ptilotopus) sponsa; f) Centris (P.) denudans; g) Centris (P.) maranhensis; h) Centris bicolor; i) Epicharis bicolor; j) Paratetrapedia leucostoma; k) Paratetrapedia (Amphipedia) sp. n.; 1) Frieseomelitta sp.; m) Augochlora sp.; n) Tetragonisca angustula; o) Trigona fulviventris; p) Trigona pallens. 
Tabela 4. Número mensal de indivíduos coletados em flores de Byrsonima umbellata.

Table 4. Monthly number of individuals collected at Byrsonima umbellata flowers.

\begin{tabular}{|c|c|c|c|c|c|c|c|c|c|}
\hline \multirow[t]{2}{*}{ Visitantes } & \multicolumn{8}{|c|}{ Meses } & \multirow[t]{2}{*}{ Total } \\
\hline & mar. & abr. & maio & jun. & jul. & ago. & set. & out. & \\
\hline \multicolumn{10}{|l|}{ APIDAE } \\
\hline \multicolumn{10}{|l|}{ Centridini } \\
\hline Centris (Centris) aenea Lepeletier & - & - & - & 32 & 7 & 8 & 2 & 1 & 50 \\
\hline Centris (Centris) decolorata Lepeletier & - & - & - & 6 & - & 1 & - & - & 7 \\
\hline Centris (Centris) flavifrons (Fabricius) & - & - & 1 & - & - & - & - & - & 1 \\
\hline Centris (Centris) spilopoda Moure & - & - & - & - & - & 3 & - & - & 3 \\
\hline Centris (Hemisiella) tarsata Smith & - & - & - & 1 & 2 & 6 & - & - & 9 \\
\hline Centris (Hemisiella) trigonoides Lepeletier & - & - & - & 1 & - & - & 1 & - & 2 \\
\hline Centris (Heterocentris) analis (Fabricius) & - & - & - & 1 & - & - & - & - & 1 \\
\hline Centris (Ptilotopus) denudans Lepeletier & - & 1 & - & - & 1 & 2 & - & - & 4 \\
\hline Centris (Ptilotopus) maranhensis Ducke & - & - & 10 & 25 & 22 & 2 & - & - & 59 \\
\hline Centris (Ptilotopus) sponsa Smith & - & - & - & 2 & 12 & 9 & - & - & 23 \\
\hline Centris (Trachina) fuscata Lepeletier & - & - & - & 1 & 2 & - & - & - & 3 \\
\hline Centris (Trachina) longimana Fabricius & - & - & - & 3 & - & - & - & - & 3 \\
\hline Centris (Xanthemisia) bicolor Lepeletier & - & - & - & - & 1 & - & - & 1 & 2 \\
\hline Centris (Trachina) sp.n. & - & - & - & - & 5 & 12 & 1 & - & 18 \\
\hline Centris sp.1 & - & - & - & 1 & - & - & - & - & 1 \\
\hline Centris sp.2 & - & - & - & - & - & - & 1 & - & 1 \\
\hline Centris sp.3 & - & - & - & - & - & - & 1 & - & 1 \\
\hline Epicharis (Epicharis) bicolor Smith & - & - & 1 & 4 & - & - & - & - & 5 \\
\hline Epicharis (Triepicharis) analis Lepeletier & - & - & 1 & - & - & - & - & - & 1 \\
\hline \multicolumn{10}{|l|}{ Meliponini } \\
\hline Frieseomelitta flavicornis (Fabricius) & - & - & - & - & 2 & - & - & - & 2 \\
\hline Frieseomelitta silvestrii (Friese) & - & - & 2 & 6 & - & - & - & - & 8 \\
\hline Frieseomelitta sp. & - & 5 & 6 & 11 & 17 & 2 & - & - & 41 \\
\hline Paratrigona lineata (Lepeletier) & - & 1 & 1 & 2 & - & - & - & - & 4 \\
\hline Partamona sp. & - & - & - & 1 & - & - & - & - & 1 \\
\hline Tetragona quadrangula (Lepeletier) & - & - & - & 2 & 1 & - & - & - & 3 \\
\hline Tetragonisca angustula (Latreille) & - & - & - & - & 4 & - & - & - & 4 \\
\hline Trigona fulviventris Guérin & 3 & 16 & 39 & 23 & 52 & 8 & 22 & 1 & 164 \\
\hline Trigona pallens (Fabricius) & 15 & 58 & 63 & 59 & 25 & 18 & 1 & 1 & 240 \\
\hline Trigonisca intermedia Moure & 1 & - & - & - & - & - & - & - & 1 \\
\hline Trigonisca sp. n. & - & 5 & - & - & - & - & - & - & 5 \\
\hline \multicolumn{10}{|l|}{ Tapinotaspidini } \\
\hline Paratetrapedia (Amphipedia) sp.n. & - & 2 & - & 3 & 1 & 2 & - & - & 8 \\
\hline Paratetrapedia leucostoma (Cockerell) & 2 & 28 & 7 & 6 & 7 & 2 & - & - & 52 \\
\hline Paratetrapedia testacea (Smith) & - & - & - & 1 & - & - & - & - & 1 \\
\hline Paratetrapedia sp.1 & 1 & 6 & 2 & 4 & 7 & 1 & - & - & 21 \\
\hline Paratetrapedia sp.2 & - & 15 & 6 & 2 & - & - & - & - & 23 \\
\hline \multicolumn{10}{|l|}{ Tetrapediini } \\
\hline Tetrapedia diversipes Klug & 1 & 19 & 2 & 3 & - & 5 & 1 & - & 31 \\
\hline Tetrapedia sp.1 & - & 1 & 1 & 1 & - & - & - & - & 3 \\
\hline Tetrapedia sp. 2 & - & - & 1 & 1 & - & - & - & - & 2 \\
\hline \multicolumn{10}{|l|}{ HALICTIDAE } \\
\hline \multicolumn{10}{|l|}{ Augochlorini } \\
\hline Augochlora sp.1 & 1 & 2 & - & - & 1 & 1 & - & - & 5 \\
\hline Augochlora sp.2 & - & 2 & - & - & - & - & - & - & 2 \\
\hline Augochlora sp.3 & - & 1 & 3 & 6 & 11 & 4 & - & - & 25 \\
\hline Augochlora sp.4 & - & - & - & - & - & 1 & - & - & 1 \\
\hline Total & 24 & 162 & 146 & 208 & 180 & 87 & 30 & 4 & 841 \\
\hline
\end{tabular}


Tabela 5. Número mensal de indivíduos coletados em flores de Byrsonima rotunda.

Table 5. Monthly number of individuals collected at Byrsonima rotunda flowers.

\begin{tabular}{|c|c|c|c|c|c|c|}
\hline \multirow{2}{*}{\multicolumn{2}{|c|}{ Visitantes }} & \multicolumn{4}{|c|}{ Outubro } & \multirow[t]{2}{*}{ Total } \\
\hline & & $1^{\mathrm{a}}$ sem. & $2^{\mathrm{a}}$ sem. & $3^{\mathrm{a}}$ sem. & $4^{\text {a }}$ sem. & \\
\hline \multicolumn{7}{|c|}{ APIDAE } \\
\hline \multicolumn{7}{|c|}{ Centridini } \\
\hline & Centris (Centris) aenea Lepeletier & 31 & 186 & 49 & 2 & 268 \\
\hline & Centris (Centris) spilopoda Moure & 2 & 3 & - & - & 5 \\
\hline & Centris (Hemisiella) tarsata Smith & 1 & 1 & - & - & 2 \\
\hline & Centris (Ptilotopus) maranhensis Ducke & - & 1 & - & - & 1 \\
\hline & Centris (Ptilotopus) sponsa Smith & - & 2 & - & - & 2 \\
\hline & Centris (Trachina) sp. n. & - & 4 & 1 & - & 5 \\
\hline & Centris (Xanthemisia) bicolor Lepeletier & 1 & - & - & - & 1 \\
\hline & Epicharis (Epicharis) bicolor Smith & - & 3 & 1 & - & 4 \\
\hline \multicolumn{7}{|c|}{ Meliponini } \\
\hline & Frieseomelitta flavicornis (Fabricius) & - & - & 1 & - & 1 \\
\hline & Tetragona quadrangula (Lepeletier) & - & 1 & - & - & 1 \\
\hline & Trigona fulviventris Guérin & - & 1 & - & 2 & 3 \\
\hline & Trigona fuscipennis Friese & 1 & - & - & - & 1 \\
\hline & Trigona pallens (Fabricius) & - & 13 & - & - & 13 \\
\hline \multicolumn{7}{|c|}{ Tapinotaspidini } \\
\hline & Paratetrapedia (Amphipedia) sp. n. & - & 1 & - & - & 1 \\
\hline & Paratetrapedia sp.1 & - & 1 & - & - & 1 \\
\hline & Xanthopedia globulosa (Friese) & - & 1 & - & - & 1 \\
\hline Total & & 36 & 218 & 52 & 4 & 310 \\
\hline
\end{tabular}

grãos de pólen no corpo e de contato com os estigmas foi a porção ventral do tórax.

A maioria das espécies de Meliponini visitou as flores de B. umbellata e B. rotunda apenas para coleta de pólen, com exceção de Frieseomelitta sp., que foi observada sobre os elaióforos das flores de B. umbellata, exibindo comportamento de coleta de óleo através de raspagem com as mandíbulas (Figura 2). Para a coleta de pólen elas pousam sobre as anteras e retiram os grãos com a língua, podendo fazer o mesmo por fora deles; depois os transferem para a corbícula nas pernas posteriores. Estas abelhas podem ainda perfurar as pétalas do botão e introduzir sua língua roubando pólen, sendo assim consideradas pilhadoras.

As abelhas da tribo Tapinotaspidini e Tetrapediini visitaram as flores de Byrsonima para coleta de pólen e de óleo. Durante a coleta de pólen, prendem-se aos filetes dos estames com as mandíbulas e, com os pentes basitarsais anteriores, raspam os grãos das anteras, ficando com a porção anterior da cabeça impregnada de pólen, podendo entrar em contato com os estigmas e promover a polinização. A transferência para a escopa ocorre com auxílio das pernas medianas, sem a abelha sair da flor. Paratetrapedia leucostoma (Cockerell) foi observada nas flores de B. umbellata coletando pólen por fora dos estames com a língua, sendo considerada pilhadora (Figura 2).

Já a coleta de óleo pode ser feita tanto no botão quanto na flor, pelo lado externo, não contatando as partes reprodutivas das flores, neste caso podendo atuar como pilhadoras. As abelhas prendem-se aos elaióforos com auxílio das mandíbulas e com os pentes basitarsais raspam as glândulas, coletando o óleo e transferindo-o sem sair da flor ou do botão.

Os representantes da tribo Augochlorini só foram observados coletando pólen nas flores de B. umbellata (Figura 2). Para isso eles pousam sobre os estames, prendendo-se com as mandíbulas nas anteras, realizando movimentos de vibração do corpo. Dessa forma, os grãos de pólen são liberados, aderindo-se por todo o corpo da abelha, sendo posteriormente transferidos, nas flores ou em folhas próximas, para as escopas.

\section{Discussão}

\section{Fenologia}

De acordo com a classificação de Newstrom et al. (1994), o padrão de floração de $B$. umbellata é anual, regular e extensivo. $\mathrm{O}$ período de floração coincidiu com o observado por Barros (1992) no cerrado de Brasília: de abril a setembro e de maio a outubro. Ou seja, as abelhas visitantes desta espécie dispõem de recursos por um período de seis a sete meses. Além disso, B. umbellata apresenta alta sincronia de eventos fenológicos e um grande número de flores abertas por indivíduo e entre os indivíduos, tornando ainda mais alta a quantidade de pólen e óleo disponível para os visitantes na população. Uma grande e contínua oferta de flores funciona como importante fator para a manutenção e sobrevivência de populações de abelhas coletoras de óleo, cujos imaturos dependem fundamentalmente deste recurso para completar seu ciclo de vida (Buchmann 1987, Vinson et al. 1997), sendo os Centridini o grupo mais representativo dentre os visitantes das espécies de Byrsonima.

Este padrão de floração foi também encontrado em $B$. sericea em Floresta Atlântica (Teixeira \& Machado 2000), B. coccolobifolia, B. crassa Nied., B. guilleminiana A. Juss., B. laxiflora Griseb., B. subterranea Brade \& Markgr., B. verbascifolia Rich. ex Juss. numa área de Cerrado (Barros 1992) e B. coccolobifolia em savana amazônica (Benezar \& Pessoni 2006), sendo possivelmente uma estratégia comum nas plantas do gênero e independente do tipo vegetacional, de solo ou clima (Bezerra et al. 2009). 
Já B. rotunda apresentou padrão de floração anual, regular e curto, porém florescendo logo após ocorrência de fogo, quando há pouca ou nenhuma outra planta florida, o que faz desta espécie a única fonte de recursos disponível para as abelhas no período pós-queimada. O fato de $B$. rotunda florescer após episódio de incêndio, nos leva a presumir que esta espécie apresenta floração estimulada pela ocorrência de fogo, como observado para outras espécies de Cerrado (Fiedler et al. 2004, Schmidt et al. 2005). Byrsonima coccolobifolia, por exemplo, apresentou adaptação ao fogo na savana amazônica (Benezar \& Pessoni 2006), onde os indivíduos floresceram intensamente após o incêndio. Porém, convém ressaltar que foram feitos dois anos de observação fenológica, sendo importante pelo menos mais um ano de acompanhamento para constatar que a floração de $B$. rotunda é realmente estimulada pelo fogo.

As duas espécies floresceram uma após a outra e de forma sincrônica. Floração sequencial também foi observada por Barros (1992) em sete espécies simpátricas de Byrsonima no cerrado de Brasília e por Costa et al. (2006) em cinco espécies de Malpighiaceae nas dunas de Abaeté (BA). De acordo com Janzen (1980), a produção sincronizada de flores de espécies diferentes, por curto período de tempo, poderia atrair a atenção de polinizadores menos especializados, enquanto as espécies cujo florescimento ocorre de forma assincrônica atrairiam polinizadores especialistas.

Tanto a floração quanto a frutificação de $B$. umbellata tiveram início no período chuvoso, estendendo-se até o período de estiagem, com pico no período de transição. Já $B$. rotunda floresceu e frutificou apenas no período de estiagem. Das sete espécies de Byrsonima estudadas por Barros (1992), apenas B. laxiflora floresceu na época chuvosa no cerrado. Em uma savana amazônica (RO), B. coccolobifolia floresceu no meio da estação seca (Benezar \& Pessoni 2006), assim como B. crassifolia também floresceu na estação seca em ambiente de dunas (CE) (Pereira \& Freitas 2002).

Em uma comunidade vegetal, geralmente a floração se distribui ao longo do ano, de modo que haja fornecimento de recursos para os diversos polinizadores (Antunes \& Ribeiro 1999). Em áreas de cerrado, onde existe estação seca e estação chuvosa bem definidas, a maioria das plantas floresce na estação seca (Frankie et al. 1974) ou no início da estação chuvosa (Oliveira 1998, Batalha \& Mantovani 2000). A atividade dos insetos polinizadores seria favorecida durante esse período devido à falta de chuvas pesadas que danificariam as flores e à queda das folhas que tornaria as flores mais visíveis (Janzen 1980).

Já a frutificação é sazonal, sendo os frutos carnosos zoocóricos geralmente produzidos durante a estação chuvosa e os secos, anemo ou autocóricos, durante a seca (Oliveira 1998, Batalha \& Mantovani 2000). A dispersão durante a estação seca torna a espécie importante fonte de recurso para diversos grupos de animais silvestres (aves, morcegos, macacos) (Almeida et al. 1998), em um período em que geralmente há menor proporção de espécies zoocóricas dispersando os diásporos (Silberbauer-Gottsberger \& Gottsberger 1988, Batalha \& Mantovani 2000). Segundo Felfili et al. (1999), a maturação e a dispersão dos frutos na estação seca e transição seca-chuva aumentam as chances de germinação e crescimento de plântulas, quando as sementes são beneficiadas pela umidade e abundância de nutrientes liberados a partir da decomposição da serapilheira acumulada na estação seca. Além disso, as plântulas que emergem no início da estação chuvosa encontram condições ambientais mais favoráveis ao estabelecimento, pois poderão desenvolver sistemas radiculares profundos antes da próxima seca. Ou seja, a fenologia reprodutiva das plantas que vivem em habitats sazonais tem sido moldada para sincronizar a maturação dos frutos e a liberação das sementes com a época mais favorável para o crescimento e a sobrevivência das plântulas (Antunes \& Ribeiro 1999, Pirani et al. 2009).

\section{Morfologia e biologia floral}

As características florais das duas espécies de Byrsonima se enquadram na síndrome de melitofilia (sensu Faegri \& Pijl 1979), sendo padrão na família Malpighiaceae (Anderson 1979, 1981). Esse conservadorismo floral pode ser resultado da evolução das Malpighiaceae neotropicais com polinizadores especializados (Anderson 1979). A presença de uma pétala modificada em forma de estandarte é interpretada como guia de orientação para pouso e posicionamento do polinizador (geralmente abelha) na flor, possuindo ainda função de apoio durante a coleta de óleo, onde a abelha se prende com a mandíbula (Anderson 1979, Sazima \& Sazima 1989, Vogel 1990). Neste trabalho, várias espécies de abelhas Centridini exibiram este tipo de comportamento, ao contrário do observado em espécies simpátricas de Malpighiaceae em dunas costeiras da Bahia por Costa et al. (2006), em que na maioria das visitas as abelhas não se prenderam à pétala modificada durante a coleta de óleo.

Antese diurna também foi verificada no cerrado de Brasília por Barros (1992), em espécies simpátricas de Byrsonima, inclusive $B$. umbellata. Diferente da maioria das espécies de Byrsonima, Benezar \& Pessoni (2006) observaram que a antese em B. coccolobifolia iniciava-se por volta das 16 horas e terminava na madrugada seguinte; porém, após uma queimada na área de estudo (Savana), o processo ocorreu em horários variados do dia.

A mudança de cor nas flores de Byrsonima durante a antese foi observada em outras espécies, tais como B. gardnerana, B. microphylla A. Juss., B. crassifolia e B. coccolobifolia (Benezar \& Pessoni 2006, Costa et al. 2006, Rêgo \& Albuquerque 2006, Bezerra et al. 2009), sendo importante no efeito de atração das abelhas. A mudança na coloração floral evoluiu, de acordo com Weiss (1995), provavelmente em resposta à seleção por polinizadores e reflete uma convergência funcional dentro das angiospermas. Segundo Anderson (1979), a mudança de coloração apresentada por flores de Malpighiaceae, é um indício de adaptação que visa redirecionar os visitantes às flores novas, ampliando o número de flores visitadas (van Doorn 1997), evitando ainda a remoção dos grãos já depositados no estigma e possíveis danos às estruturas reprodutivas (McDade \& Kinsman 1980).

Em relação ao odor, este pode ser fraco, doce ou ligeiramente desagradável e forte, e ainda em algumas espécies estranho e difícil de definir, sendo muitas vezes imperceptível ou semelhante a grama ou vegetação verde (Gottsberger \& Silberbauer-Gottsberger 2006). Em campo não foi detectado nenhum odor nas flores das espécies estudadas, sendo recomendável a utilização de uma técnica para detecção de osmóforos nas flores que confirme a presença ou ausência de emissão de odor.

Organismos têm uma quantidade limitada de tempo e energia disponíveis, de modo que cada estratégia representa uma alocação ou partição desse tempo e energia (Cody 1966), havendo de acordo com Pianka (1970) dois tipos de estratégias: organismos com estratégia $\mathrm{r}$, que alocam mais recursos para a reprodução, e com estratégia $\mathrm{K}$, que alocam menos. $B$. rotunda produz maior número de flores, as quais abrem pela manhã e pela tarde, possuindo grande quantidade de recursos para os visitantes. Porém esses recursos estão disponíveis por um curto período de floração. Presume-se que esta espécie investe mais em quantidade de flores, de forma que, mesmo diante do curto período, as chances de uma maior produção de frutos se mantenham. Já em B. umbellata as flores se abrem somente pela manhã e estão em menor quantidade, porém essas flores possuem maior tamanho e a planta se encontra florida por mais tempo, havendo constante renovação dos recursos. Ou seja, esta espécie investe mais em qualidade do que em quantidade de flores. Enfim, as duas espécies de Byrsonima possuem estratégias de reprodução diferentes (Tabela 6), de modo a sustentar os serviços de polinização e, consequentemente, obter sucesso na produção de frutos e na reprodução. 
Tabela 6. Características reprodutivas de Byrsonima umbellata e B. rotunda (Malpighiaceae) em área de Cerrado no município de Urbano Santos, MA.

Table 6. Reproductive characteristics of Byrsonima umbellata and B. rotunda (Malpighiaceae) in an area of Cerrado, at the municipality of Urbano Santos, MA.

\begin{tabular}{lcc}
\hline \multicolumn{1}{c}{ Características } & Byrsonima umbellata & Byrsonima rotunda \\
\hline Período de floração & mar.-out. & out. \\
Quantidade de flores & 419 (média) & 5655 (média) \\
Tamanho das flores & $10,1 \pm 1,2$ & $7 \pm 0,4$ \\
Tamanho do fruto & $6,15 \pm 1,13$ & $5,25 \pm 0,78$ \\
Viabilidade polínica & $94 \%$ & $9 \%$ \\
Eficácia reprodutiva & 0,78 & 0,90 \\
Abertura floral & Manhã & Manhã e Tarde \\
Estratégia adotada & $\mathbf{r}$ & $\mathbf{K}$ \\
\hline
\end{tabular}

\section{Sistema de reprodução}

Em B. rotunda houve formação de frutos em todos os experimentos realizados, o que pode ser explicado pela alta eficiência do sistema de polinização e/ou pela ocorrência de agamospermia. Supondo que as sementes formadas por agamospermia sejam viáveis, esta seria uma maneira de garantir a reprodução na ausência de polinizadores, aumentando a capacidade reprodutiva da espécie (Piratelli et al. 1998).

A apomixia frequentemente está associada à poliploidia e origem de espécies a partir de hibridações (Nijs \& Menken 1996), o que por sua vez traz como consequência baixa fertilidade de grãos de pólen (Mogie 1992). Entre espécies tropicais, a apomixia já foi observada em Poaceae (Carneiro \& Dusi 2002), Dipterocarpaceae (Kaur et al. 1978), Melastomataceae (Renner 1989, Goldenberg \& Shepherd 1998), Bombacaceae (Oliveira et al. 1992), Clusiaceae (Ha et al. 1988), Erythroxylaceae (Berry et al. 1991), Asteraceae (Werpachowski et al. 2004), Amaryllidaceae, Anacardiaceae, Araceae, Cactaceae, Euphorbiaceae, Gentianaceae, Myrtaceae e Orchidaceae (Nygren 1954).

Das 12 espécies de Malpighiaceae neotropicais estudadas por Sigrist \& Sazima (2004), uma foi considerada agamospérmica (Banisteriopsis pubipetala Juss.), o que é de ocorrência restrita na família, sendo registrada também em poucas espécies de Peixotoa (Anderson 1982). Quanto à ocorrência de agamospermia no gênero Byrsonima, não há citação na literatura científica. Diante deste fato e visto que não foi feito um acompanhamento dos frutos formados até a dispersão nem foi verificada a viabilidade/germinação das sementes, são necessários estudos adicionais que confirmem a real capacidade de $B$. rotunda produzir frutos viáveis por apomixia.

Assim como em B. rotunda, autopolinização espontânea também já foi observada em Banisteriopsis adenopoda (A. Juss.) B. Gates, Mascagnia anisopetala (A. Juss.) Griseb. e Tetrapterys guilleminiana A. Juss. (Sigrist \& Sazima 2004). Entretanto, na maioria das Malpighiaceae estudadas, a autopolinização espontânea é limitada por hercogamia, protoginia e cutícula estigmática e pode ser um determinante significativo no comportamento reprodutivo de espécies potencialmente autocompatíveis (Heslop-Harrison \& Heslop- Harrison 1983).

Espécies autógamas apresentam vantagens ecológicas como fixação de genes favoráveis na população (Barringer 2007), "segurança reprodutiva" em ambientes com populações pequenas (Lloyd 1992), ou em períodos de ausência ou baixa frequência de polinizadores, o que dificultaria a polinização cruzada (Santos et al. 2010). Entretanto, há custos como o desconto de gametas, ou seja, pólen que poderia ser utilizado na fecundação cruzada é gasto com a autofecundação "roubando" óvulos que poderiam ser fecundados com pólen de outros indivíduos, e depressão endogâmica, caso haja genes deletérios na população (Lloyd 1992, Barringer 2007, Santos et al. 2010).

Seis espécies de Malpighiaceae apresentaram certo grau de autocompatibilidade em Campinas: Banisteriopsis adenopoda, B. lutea (Griseb.) Cuatrec. , B. muricata (Cav.) Cuatrec., Mascagnia anisopetala, Tetrapterys guilleminiana e T. phlomoides (Spreng.) Nied., porém a produção de frutos foi baixa após autopolinização dessas espécies (Sigrist \& Sazima 2004). No Cerrado de Brasília, Barros (1992) encontrou autocompatibilidade para todas as sete espécies de Byrsonima estudadas, inclusive para B. umbellata. Já espécies como Byrsonima crassifolia (Rêgo \& Albuquerque 1989), B. sericea (Teixeira \& Machado 2000, Costa et al. 2006) e B. microphylla (Costa et al. 2006) foram consideradas auto-incompatíveis (Costa et al. 2006), assim como Dicella bracteosa (A.Juss.) Griseb., Mascagnia cordifolia A.Juss., M. sepium Griseb. e Stigmaphyllon lalandianum A.Juss. (Sigrist \& Sazima 2004). Autocompatibilidade parece ser comum em espécies neotropicais de Malpighiaceae, já sendo confirmada nos gêneros Byrsonima, Banisteriopsis, Galphimia, Heteropterys, Malpighia, Peixotoa (Bawa 1974) e certamente em espécies cleistogâmicas de Aspicarpa, Camarea, Gaudichaudia e Janusia (Anderson 1980).

Benezar \& Pessoni (2006) observaram sistema reprodutivo misto em Byrsonima coccolobifolia, com níveis elevados de alogamia e autogamia, como foi encontrado em $B$. rotunda. Tal sistema combina as vantagens da autofecundação e polinização cruzada, garantindo um alto nível de adaptabilidade da população às condições vigentes do ambiente associado à manutenção de elevado potencial evolutivo através da recombinação, o que capacita a espécie para a colonização de novas e extensas áreas (Scariot et al. 1991).

O estudo da viabilidade polínica reflete a potencialidade do gameta masculino na eficiência da fecundação e posterior fertilização (Biondo \& Battistin 2001), sendo que quanto mais alta for a viabilidade maior será o índice de fertilização (Souza et al. 2002). As duas espécies de Byrsonima apresentaram diferentes viabilidades do pólen, sendo alta em B. umbellata $(94 \%)$ e baixa em B. rotunda $(9 \%)$. Por outro lado, $B$. rotunda possui alta eficiência reprodutiva, o que explica a produção de frutos em todos os experimentos de polinização. Dessa forma, a espécie assegura a sua reprodução.

Diferentes graus de compatibilidade podem ser encontrados entre as angiospermas e a distinção entre auto-incompatibilidade e autocompatibilidade é muitas vezes arbitrária, pois esses são dois extremos na variação do sistema reprodutivo e muitas espécies se situam entre eles (Bawa 1974, Borba et al. 2001). Diante disso, é necessário que mais estudos sejam feitos para se entender melhor o sistema de reprodução das Malpighiaceae neotropicais, como sugerido por Costa et al. (2006), especialmente para aquelas espécies de padrão de floração curto, como $B$. rotunda.

\section{Visitantes florais}

Levando-se em consideração o comportamento durante visitas às flores, Centris aenea e $C$. (Trachina) sp. n. foram consideradas os polinizadores mais eficientes em flores de B. umbellata e $C$. aenea de $B$. rotunda, uma vez que ao visitarem sempre contataram as estruturas reprodutivas das flores. A relação entre essas abelhas e flores de Malpighiaceae é vista como um processo de co-evolução, caracterizada pelas adaptações morfofuncionais ocorrentes em ambos os grupos (Vogel 1990, Simpson \& Neff 1981, 1983, Machado 2004).

Apesar de muito abundantes, as espécies de Meliponini observadas nas duas espécies de Byrsonima estudadas nem sempre entravam em contato com as estruturas reprodutivas da flor, sendo consideradas polinizadores ocasionais ou pilhadoras, contribuindo pouco para a polinização das espécies. Rêgo \& Albuquerque (1989) 
também observaram Trigona pallens e T. fulviventris coletando óleo e pólen em Byrsonima crassifolia, podendo provocar ocasionalmente sua polinização. De acordo com as autoras, o óleo coletado serviria para garantir adesão de pólen na superfície ventral do tórax destas abelhas, que transportariam maior quantidade de grãos de pólen para o ninho. Renner (1989) supõe que o óleo poderia ser usado na construção do ninho ou como líquido opcional para umedecer os grãos de pólen coletados. Buchmann (1987) sugere que o óleo coletado por meliponíneos seria utilizado na construção das entradas do ninho como efeito repelente sobre as formigas.

De acordo com Vogel (1974), Tetrapediini é um grupo especialista na coleta de óleo por apresentar pentes basitarsais. Porém, durante a coleta de óleo essas abelhas não agem como polinizadores, uma vez que raspam os elaióforos pela parte abaxial da flor, sem entrar em contato com as anteras e estigmas. Durante a coleta de pólen, elas podem eventualmente realizar a polinização, sendo consideradas polinizadores ocasionais, assim como as espécies de Tapinotaspidini.

A coleta de pólen por vibração também foi observada em Centridini e Augochlorini em flores de Byrsonima crassifolia (Rêgo \& Albuquerque 1989), B. gardnerana (Costa et al. 2006, Bezerra et al. 2009), B. sericea (Teixeira \& Macahdo 2000, Costa et al. 2006) e B. microphylla (Costa et al. 2006). Este tipo de coleta em flores de deiscência não-poricida foi descrito por Buchmann (1983), sendo observado em diversas espécies de abelhas (Sazima \& Sazima 1989 , Vogel \& Machado 1991, Lopes \& Machado 1996, Santos \& Machado 1998, Freitas et al. 1999).

Entre as abelhas visitantes de B. umbellata em Urbano Santos (MA) e em Brasília (DF) (Barros 1992), apenas uma espécie, Paratrigona lineata (Lepeletier), foi comum. A diversidade de abelhas visitantes de $B$. umbellata nesses dois trabalhos é expressiva, sendo que só a tribo Centridini corresponde à metade das espécies. A grande quantidade de flores e o longo período de floração de B. umbellata, favorecem a contínua visitação às plantas, uma vez que a atração exercida sobre as abelhas depende de atrativos florais, como coloração e odor, da abundância de flores e da quantidade de recursos existentes (Gumbert 2000). Diante disso, percebe-se o importante papel ecológico que $B$. umbellata possui na manutenção da fauna apícola na área de estudo.

B. rotunda apresenta curto período de floração, não possuindo uma riqueza de visitantes tão grande quando comparada à outras espécies do gênero. Porém sua floração ocorre após episódios de fogo, quando várias espécies vegetais próximas não apresentam flor, constituindo uma importante fonte de pólen e óleo para as abelhas.

Os meses de maior abundância e diversidade de abelhas em B. umbellata coincidiram com o pico de floração da espécie e de outras típicas de Cerrado na área estudada (Banisteriopsis sp., Bowdichia virgilioides Kunth., Parkia sp., Ouratea sp., etc, obs. pessoal). Além disso, floração sequencial entre as espécies (como em B. umbellata, B. crassifolia, B. rotunda, B. verbascifolia e Banisteriopsis sp., presentes na área de estudo; obs. pessoal) aumenta a oferta de recursos para os polinizadores, favorecendo a sua sobrevivência e mantendo estável a polinização das espécies envolvidas (Sigrist \& Sazima 2004).

Maior atividade de visitas às flores de espécies de Byrsonima no período matutino também foi observada por Albuquerque \& Rêgo (1989) e Teixeira \& Machado (2000), sendo um padrão considerado comum para as comunidades tropicais, visto que nesse período muitas flores estão em antese, proporcionando maior quantidade e qualidade de recursos, tais como pólen, óleo e néctar.

As duas espécies de Byrsonima estudadas são de grande importância dentro do ambiente estudado (Cerrado), por apresentarem diferentes estratégias reprodutivas e por atraírem grande diversidade de abelhas, que visitam suas flores à procura de pólen e/ou óleo.
Em contrapartida, a presença e eficácia das abelhas polinizadoras exercem papel fundamental na reprodução e manutenção não só das populações de Byrsonima, mas de muitas outras espécies vegetais presentes na mesma área.

\section{Agradecimentos}

À FAPEMA pela concessão de bolsa à primeira autora; à Comercial e Agrícola Paineiras, pela permissão para realização do trabalho na área de estudo e apoio logístico; Richardson Gomes, Marina Ramos e Adriano Maciel pela companhia e auxílio no trabalho de campo; Dr. ${ }^{a}$ Isabel Cristina Machado (UFPE), Dr. ${ }^{a}$ Emília Girnos (UFMA) e Dr. Giorgio Venturieri (EMBRAPA, Belém - PA) pela leitura e sugestões ao manuscrito.

\section{Referências Bibliográficas}

ALBUQUERQUE, P.M.C. \& RÊGO, M.M.C. 1989. Fenologia de abelhas visitantes de murici (Byrsonima crassifolia, Malpighiaceae). Bol. Mus. Para. Emilio Goeldi, Zool. 5(2):163-178.

ALMEIDA, S.P., PROENÇA, C.E.B., SANO, S.M. \& RIBEIRO, J.F. 1998. Cerrado: espécies vegetais úteis. CPAC-Embrapa, Planaltina.

ANDERSON, W.R. 1979. Floral conservation in Neotropical Malpighiaceae. Biotropica 11(3):219-223. http://dx.doi.org/10.2307/2388042

ANDERSON, W.R. 1980. Cryptic self-fertilization in Malpighiaceae. Science 207(4433):892-893. PMid:17729871. http://dx.doi.org/10.1126/ science.207.4433.892

ANDERSON, W.R. 1981. Malpighiaceae. Mem. New York Botan. G. 32:21-306.

ANDERSON, W.R. 1982. A monograph of the genus Peixotoa (Malpighiaceae). Contrib. Univ. Mich. Herb. 5:1-92.

ANTUNES, N.B. \& RIBEIRO, J.F. 1999. Aspectos fenológicos de seis espécies vegetais em matas de galeria do Distrito Federal. Pesq. Agropec. Bras. 34(9):1517-1527. http://dx.doi.org/10.1590/S0100204X1999000900001

BARRINGER, B.C. 2007. Polyploidy and self-fertilization in flowering plants. Am. J. Bot. 94:1527-1533. PMid:21636519. http://dx.doi.org/10.3732/ ajb.94.9.1527

BARROS, M.A.G. 1992. Fenologia da floração, estratégias reprodutivas e polinização de espécies simpátricas do gênero Byrsonima Rich (Malpighiaceae). Rev. Bras. Biol. 52(2):343-353.

BARROSO, G.M., PEIXOTO, A.L., ICHASO, C.L.F., GUIMARÃES, E.F., COSTA, C.G. \& LIMA, H.C. 1991. Sistemática de angiospermas do Brasil. Livros Técnicos e Científicos, Rio de Janeiro.

BATALHA, M.A. \& MANTOVANI, W. 2000. Reproductive phenological patterns of cerrado plant species at the Pé-de-Gigante Reserve (Santa Rita do Passa Quatro, SP, Brazil):a comparison between the herbaceous and woody floras. Rev. Bras. Biol. 60(1):129-145. PMid:10838932. http:// dx.doi.org/10.1590/S0034-71082000000100016

BAWA, K.S. 1974. Breeding systems of tree species of a lowland tropical community. Evolution 28(1):85-92. http://dx.doi.org/10.2307/2407241

BENCKE, C.S.C. \& MORELLATO, P.C. 2002. Comparação de dois métodos de avaliação da fenologia de plantas, sua interpretação e representação. Rev. Bras. Bot. 25(3):269-275. http://dx.doi.org/10.1590/S010084042002000300003

BENEZAR, R.M.C. \& PESSONI, L.A. 2006. Biologia floral e sistema reprodutivo de Byrsonima coccolobifolia (Kunth) em uma savana amazônica. Acta Amaz. 36(2):159-168. http://dx.doi.org/10.1590/S004459672006000200005

BERRY, P.E., TOBE, H. \& GOMEZ, J.A. 1991. Agamospermy and loss of distyly in Erythroxylum undulatum from Northern Venezuela. Am. J. Bot. 78(5):595-600. http://dx.doi.org/10.2307/2445080 
BEZERRA, E.S., LOPES, A.V. \& MACHADO, I.C. 2009. Biologia reprodutiva de Byrsonima gardneriana A. Juss. (Malpighiaceae) e interações com abelhas Centris (Centridini) no Nordeste do Brasil. Rev. Bras. Bot. 32(1):95-108. http://dx.doi.org/10.1590/S010084042009000100010

BIONDO, E. \& BATTISTIN, A. 2001. Comparação da eficiência de diferentes corantes na estimativa da viabilidade de grãos de pólen em espécies dos gêneros Eriosema (DC.) G.Don e Rhynchosia Lour (Leguminosae Faboideae), nativas na Região Sul do Brasil. Bioikos 15(1):39-44.

BORBA, E.L., SHEPHERD, G.J. \& SEMIR, J. 2001. Selfincompatibility, inbreeding depression and crossing potential in five Pleurothallis (Orchidaceae) species. Ann. Bot. 88(1):89-99. http://dx.doi.org/10.1006/ anbo.2001.1435

BUCHMANN, S.L. 1983. Buzz pollination in Angiospems. In Handbook of experimental pollination biology (C.E. Jones \& R.J. Little, eds.). Scientific and Academic Editions, New York, p.73-113.

BUCHMANN, S.L. 1987. The ecology of oil flowers and their bees. Annu. Rev. Ecol. Syst. 18:343-369. http://dx.doi.org/10.1146/annurev. es.18.110187.002015

CARNEIRO, V.T.C. \& DUSI, D.M.A. 2002. Apomixia: em busca de tecnologias de clonagem de plantas por sementes. Biotec. Ciênc. Desenvolv. 25:36-42.

CODY, M.L. 1966. A general theory of clutch size. Evolution 20:174-184. http://dx.doi.org/10.2307/2406571

COSTA, C.B.N., COSTA, J.A.S. \& RAMALHO, M. 2006. Biologia reprodutiva de espécies simpátricas de Malpighiaceae em dunas costeiras da Bahia, Brasil. Rev. Bras. Bot. 29(1):103-114. http://dx.doi.org/10.1590/ S0100-84042006000100010

DAFNI, A. 1992. Pollination ecology: a practical approach. Oxford University Press, New York.

DAFNI, A., PACINI, E. \& NEPI, M. 2005. Pollen and stigma biology. In Practical Pollination Biology (DAFNI, A., KEVAN, P.G. \& HUSBAND, B.C.E eds.). Enviroquest, Ontario, p.83-146.

DAVIS, C.C., ANDERSON, W.R. \& DONOGHUE, M.J. 2001. Phylogeny of Malpighiaceae: evidence from chloroplast $n d h F$ and $t r n l-F$ nucleotide sequences. Am. J. Bot. 88(10):1130-1846. PMid:21669617. http://dx.doi. org/10.2307/3558360

FAEGRI, K. \& PIJL, L.VAN DER. 1979. The principles of pollination ecology. Pergamon Press, Oxford.

FELFILI, J.M., SILVA JUNIOR, M.C., DIAS, B.J. \& REZENDE, A.V. 1999. Estudo fenológico de Stryphnodendron adstringens (Mart.) Coville no cerrado sensu stricto da fazenda Água Limpa no Distrito Federal, Brasil. Rev. Bras. Bot. 22(1): 83-90.http://dx.doi.org/10.1590/S010084041999000100011

FIEDLER, N.C., AZEVEDO, I.N.C., REZENDE, A.V., MEDEIROS, M.B. \& VENTUROILI, F. 2004. Efeito de incêndios florestais na estrutura e composição florística de uma área de cerrado sensu stricto na Fazenda Água Limpa, DF. Rev. Árvore 28(1):129-138. http://dx.doi.org/10.1590/ S0100-67622004000100017

FLINTE, V., ARAÚJO, C.O., MACEDO, M.V. \& MONTEIRO, R.F. 2003. Comunidade de insetos associada a Byrsonima sericea (Malpighiaceae) na Restinga de Jurubatiba, RJ: observações preliminares. In VI Congresso de Ecologia do Brasil (V. Claudino-Sales, I. M. Tonini \& E. W. C. Dantas, eds.). Universidade Federal do Ceará/ Sociedade de Ecologia do Brasil, Fortaleza, p.304-305.

FRANKIE, G.W., BAKER, H.G. \& OPLER, P.A. 1974. Comparative phonological studies of trees in tropical wet and dry forests in the lowlands of Costa Rica. J. Ecol. 62(3):881-919. http://dx.doi.org/10.2307/2258961

FREITAS, B.M., ALVES, J.E., BRANDÃO, G.F. \& ARAÚJO, Z. B. 1999. Pollination requirements of West Indian cherry (Malpighia emarginata) and its putative pollinators, Centris bees, in NE Brazil. J. Agric. Sci. 133(3):303-311. http://dx.doi.org/10.1017/S0021859699006930

GOLDENBERG, R. \& SHEPHERD, G.J. 1998. Studies on the reproductive biology of Melastomataceae in "cerrado" vegetation. Plant Syst. Evol. 211:13-29.
GOTTSBERGER, G. \& SILBERBAUER-GOTTSBERGER, I. 2006. Oilflowers and oil-collecting bees. In Life in the cerrado - a South American Tropical Seasonal Ecosystem. Vol. II. Pollination and seed dispersal. (G. Gottsberger \& I. Silberbauer-Gottsberger, eds.). Reta Verlag, Ulm, p.112-115.

GUMBERT, A. 2000. Color choices by bumble bees (Bombus terrestris):innate preferences and generalization after learning. Behav. Ecol. Sociobiol. 48(1):36-43. http://dx.doi.org/10.1007/s002650000213

HA, C.O., SANDS, V.E., SOEPADMO, E. \& JONG, K. 1988. Reproductive patterns of selected understorey trees in the Malaysian rain forest: the apomictic species. Bot. J. Linn. Soc. 97:317-331. http://dx.doi. org/10.1111/j.1095-8339.1988.tb01586.x

HESLOP-HARRISON, J. \& HESLOP-HARRISON, Y. 1983. Pollen-stigma interaction in the Leguminosae: the organization of the stigma in Trifolium pretense L. Ann. Bot. 51:571-583.

JANZEN, D. H. 1980. Ecologia vegetal nos trópicos. EPU, EdUSP, São Paulo.

KAUR, A., HA, C.O., JONG, K., SANDS, V.E., CHAN, H.T., SOEPADMO, E. \& ASHTON, P.S. 1978. Apomixis may be widespread among trees of the climax rain forest. Nature 271:440-442. http://dx.doi. org/10.1038/271440a0

LLOYD, D.G. 1992. Self- and cross-fertilization in plants. II. The selection of self-fertilization. Int. J. Plant Sci. 151:370-380. http://dx.doi. org/10.1086/297041

LOMBELLO, R.A. \& FORNI-MARTINS, E.R. 2003. Malpighiaceae: correlations between habit, fruit type and basic chromosome number. Acta Bot. Bras. 17(2):171-178. http://dx.doi.org/10.1590/S010233062003000200001

LOPES, A.V.F. \& MACHADO, I.C. 1996. Biologia floral de Swartzia pickelii Killip ex Ducke (Leguminosae-Papilionoideae) e sua polinização por Eulaema spp. (Apidae-Euglossini). Rev. Bras. Bot. 19(1):17-24.

MACHADO, C.G. \& SEMIR, J. 2006. Fenologia da floração e biologia floral de bromeliáceas ornitófilas de uma área de Mata Atlântica do Sudeste brasileiro. Rev. Bras. Bot. 29(1):163-174. http://dx.doi.org/10.1590/ S0100-84042006000100014

MACHADO, I.C. 2004. Oil-collecting bees and related plants: a review of the studies in the last twenty years and case histories of plants occurring in NE Brazil. In Solitary bees. Conservation, rearing and management for pollination (B.M. Freitas \& J.O.P. Pereira, eds.). Imprensa Universitária, Fortaleza, p.255-280.

MARANHÃO (Estado). 1984. Secretaria do Estado do Meio Ambiente e Turismo do Maranhão - SEMATUR. Diagnóstico dos principais problemas do Estado do Maranhão. Lithograf, São Luís.

MAUÉS, M.M. \& COUTURIER, G. 2002. Biologia floral e fenologia reprodutiva do camu-camu (Myrciaria dúbia (H.B.K.) McVaugh, Myrtaceae) no Estado do Pará, Brasil. Rev. Bras. Bot. 25(4):441-448.

MCDADE, L. \& KINSMAN, S. 1980. The impact of floral parasitism in two neotropical hummingbird pollinated plan species. Evolution 34(5):944958. http://dx.doi.org/10.2307/2408000

MOGIE, M. 1992. The evolution of asexual reproduction in plants. Chapman \& Hall, London.

NEFF, J.L. \& SIMPSON, B.B. 1981. Oil-collecting structures in the Anthophoridae (Hymenoptera):morphology, function, and use in systematic. J. Kansas Entomol. Soc. 54(1):95-123.

NEWSTROM, L.E., FRANKIE, G.W. \& BAKER, H.G. 1994. A new classification for plant phenology based in flowering patterns in lowland tropical rain forest trees at La Selva, Costa Rica. Biotropica 26(2):141159. http://dx.doi.org/10.2307/2388804

NIJS, H.C.M. \& MENKEN, S.B.J. 1996. Relations between breeding system, ploidy level, and taxonomy in some advanced sections of Taraxacum. In Compositae: Systematics (H.D.N. HIND \& H.J. BEENTJE, eds.). Royal Botanic Gardens, Kew, p.665-677.

NYGREN, A. 1954. Apomixis in Angiosperms. Part II. Bot. Rev. 20:577-649. http://dx.doi.org/10.1007/BF02958805

OLIVEIRA, P.O.1998. Fenologia e biologia reprodutiva das espécies de cerrado. In Cerrado: ambiente e flora (S.M. Sano \& S.P. Almeida, eds). Embrapa-CPAC, Planaltina, p.169-192. 
OLIVEIRA, P.E.A.M., GIBBS, P.E., BARBOSA, A.A. \& TALAVERA S. 1992. Contrasting breeding systems in two Eriotheca (Bombacaceae) species of the Brazilian cerrados. Plant Syst. Evol. 179:207-219. http:// dx.doi.org/10.1007/BF00937597

PEREIRA, J.O.P. \& FREITAS, B.M. 2002. Estudo da biologia floral e requerimentos de polinização do muricizeiro (Byrsonima crassifolia $\mathrm{L}$.). Rev. Cienc. Agron. 33(2):5-12.

PIANKA, E.R. 1970. On r- and K-selection. Am. Naturalist 104:592-597. http://dx.doi.org/10.1086/282697

PIRANI, F.R., SANCHEZ, M. \& PEDRONI, F. 2009. Fenologia de uma comunidade arbórea em cerrado sentido restrito, Barra do Garças, MT, Brasil. Acta Bot. Bras. 23(4):1096-1109. http://dx.doi.org/10.1590/ S0102-33062009000400019

PIRATELLI, A.J., PIÑA-RODRIGUES, F.C.M., GANDARA, F.B., SANTOS, E.M.G. \& COSTA, L.G.S. 1998. Biologia da polinização de Jacaratia spinosa (Aubl) Adc. (Caricaceae) em mata residual do sudeste brasileiro. Rev. Bras. Biol. 58(4):671-679. http://dx.doi.org/10.1590/S003471081998000400015

RÊGO, M.M.C. \& ALBUQUERQUE, P.M.C. 1989. Comportamento das abelhas visitantes de murici, Byrsonima crassifolia (L.) Kunth, Malpighiaceae. Bol. Mus. Para. Emilio Goeldi, Zool. 5(2):179-193.

RÊGO, M. \& ALBUQUERQUE, P. 2006. Polinização do murici. EdUFMA, São Luís.

RENNER, S.S. 1989. A survey of reproductive biology in Neotropical Melastomataceae and Memecylaceae. Ann. Mo. Bot. Gard. 76(2):496518. http://dx.doi.org/10.2307/2399497

RODARTE, A.T.A., SILVA, F.O. \& VIANA, B.F. 2008. A flora melitófila de uma área de dunas com vegetação de caatinga, Estado da Bahia, Nordeste do Brasil. Acta Bot. Bras. 22(2):301-312. http://dx.doi.org/10.1590/ S0102-33062008000200001

ROSA, J. F. \& RAMALHO, M. 2007. Sucesso reprodutivo de Byrsonima sericea DC. (Malpighiaceae) e diversidade de abelhas Centridini (Apidae). Rev. Bras. Bioc. 5(1):168-170.

SANTOS, A.P.M., ROMERO, R. \& OLIVEIRA, P.E.A.M. 2010. Biologia reprodutiva de Miconia angelana (Melastomataceae), endêmica da Serra da Canastra, Minas Gerais. Rev. Brasil. Bot.33(2):333-341. http://dx.doi. org/10.1590/S0102-33061998000400014

SANTOS, M.J.L. \& MACHADO, I.C. 1998. Biologia floral e heterostilia em Vismia guianensis (Aubl.) Choisy (Clusiaceae). Acta Bot. Bras. 12(4):451-464.

SAZIMA, M. \& SAZIMA, I. 1989. Oil-gathering bees visit flowers of eglandular morphs of the oil-producing Malpighiaceae. Bot. Acta 102:106-111

SCARIOT, A.O., LLERAS, E. \& HAY, J.D. 1991. Reproductive biology of the palm Acrocomia aculeata in Central Brazil. Biotropica 23(1):12-22 http://dx.doi.org/10.2307/2388683
SCHMIDT, I.B., SAMPAIO, A.B. \& BORGHETTI, F. 2005. Efeitos da época de queima sobre a reprodução sexuada e estrutura populacional de Heteropterys pteropetala (Adr. Juss.), Malpighiaceae, em áreas de Cerrado sensu stricto submetidas a queimas bienais. Acta Bot. Bras. 19(4):927934. http://dx.doi.org/10.1590/S0102-33062005000400027

SIGRIST, M.R. \& SAZIMA, M. 2004. Pollination and reproductive biology of twelve species of Neotropical Malpighiaceae: stigma morphology and its implications for the breeding system. Ann. Bot. 94(1):33-41. PMid:15194562. http://dx.doi.org/10.1093/aob/mch108

SILBERBAUER-GOTTSBERGER, I. \& GOTTSBERGER, G. 1988. A polinização de plantas do errado. Rev. Bras. Biol. 48:651-663.

SIMPSON, B.B. \& NEFF, J.L. 1981. Floral rewards: alternatives to pollen and nectar. Ann. Mo. Bot. Gard. 68:301-322. http://dx.doi. org/10.2307/2398800

SIMPSON, B.B. \& NEFF, J.L. 1983. Evolution and diversity of floral rewards. In Handbook of experimental pollination biology (C.E. JONES \& R.J. LITTLE, eds.). Scientific and Academic Editions, New York, p.142-159.

SOBREVILA, C. \& ARROYO, M.T.K. 1982. Breeding systems in a montane tropical cloud forest in Venezuela. Plant Syst. Evol. 140:19-37. http:// dx.doi.org/10.1007/BF02409895

SOUZA, M.M.; PEREIRA, T.N.S. \& MARTINS, E.R. 2002. Microsporogênese e microgametogênese associadas ao tamanho do botão floral e da antera e viabilidade polínica em maracujazeiro-amarelo (Passiflora edulis Sims f. flavicarpa degener). Ciênc. Agrotec. 26(6):1209-1217.

TEIXEIRA, L.A.G. \& MACHADO, I.C. 2000. Sistema de polinização e reprodução de Byrsonima sericea DC (Malpighiaceae). Acta Bot. Bras. 14(3):347-357. http://dx.doi.org/10.1590/S010233062000000300011

VAN DOORN, W.G. 1997. Effects of pollination on floral attraction and longevity. J. Exp. Bot. 48:1615-1622.

VINSON, S.B., WILLIANS, H.J., FRANKIE, G.W. \& SHRUM, G. 1997. Floral lipid chemistry of Byrsonima crassifolia (Malpighiaceae) and a use floral lipids by Centris bees (Hymenoptera: Apidae). Biotropica 29(1):7683. http://dx.doi.org/10.1111/j.1744-7429.1997.tb00008.x

VOGEL, S. 1974. Ölblumen und ölsammelnde Bienen. Trop. Subtrop. Pflanzenwelt 7:285-369.

VOGEL, S. 1990. History of the Malpighiaceae in the light of pollination ecology. Mem. New York Botan. G. 55:130-142.

VOGEL, S. \& MACHADO, I.C. 1991. Pollination of four sympatric species of Angelonia (Scrophulariaceae) by oil-collecting bees in NE Brazil. Plant Syst. Evol. 178:153-178.

WEISS, M.R. 1995. Floral color change: a widespread functional convergente. Am. J. Bot. 82:167-185. http://dx.doi.org/10.2307/2445525

WERPACHOWSKI, J.S., VARASSIN, I.G. \& GOLDENBERG, R. 2004. Ocorrência de apomixia e partenocarpia em algumas espécies subtropicais de Asteraceae. Rev. Bras. Bot. 27(3):607-613. http://dx.doi.org/10.1590/ S0100-84042004000300020 
